Full Paper

\title{
Electrochemical Behavior of Thalidomide at a Glassy Carbon Electrode
}

\author{
S. Carlos B. Oliveira, ${ }^{\mathrm{a}}$ Marilene Vivan, ${ }^{\mathrm{b}}$ Ana Maria Oliveira-Brett ${ }^{\mathrm{a} *}$ \\ a Departamento de Química, Faculdade de Ciências e Tecnologia, Universidade de Coimbra, 3004-535 Coimbra, Portugal \\ b Hospital da Universidade de Coimbra, 3000 Coimbra, Portugal \\ *e-mail: brett@ci.uc.pt
}

Received: July 23, 2008

Accepted: September 1, 2008

\begin{abstract}
Thalidomide is an oral drug marketed in the 1950 s as a sedative and an anti-emetic during pregnancy that was removed from the market when its teratogenic side effects appeared in new born children due to inadequate tests to assess the drug's safety. Recent studies evaluating the use of thalidomide in cancer and HIV diseases have sparked renewed interest. The electrochemical behavior of thalidomide on a glassy carbon electrode has been investigated using cyclic, differential and square-wave voltammetry in aqueous media at different pHs. The oxidation mechanism of thalidomide is an irreversible, adsorption-controlled process, $\mathrm{pH}$ dependent up to values close to the $\mathrm{pK}_{\mathrm{a}}$ and occurs in two consecutive charge transfer reactions. A mechanism of oxidation of thalidomide involving one electron and one proton to produce a cation radical, which reacts with water and yields a final hydroxylated product is proposed. The reduction of thalidomide is also a $\mathrm{pH}$ dependent, irreversible process and occurs in a single step, with the same number of electrons and protons transferred. The reduction mechanism involves the protonation of the nitrogen that bridges the two cyclic groups, and the product of the protonation reaction causes irreversible dissociation. Both thalidomide and the non electroactive oxidation and reduction products are strongly adsorbed on the glassy carbon electrode surface.
\end{abstract}

Keywords: Thalidomide, Voltammetry, Oxidation mechanism, Reduction mechanism, Adsorption process

DOI: 10.1002/elan.200804344

\section{Introduction}

Originally developed in the 1950 's, as a sedative and antiemetic drug to combat morning sickness during pregnancy, thalidomide (TD) [1,3-dioxo-2-(2',6'-dioxopiperidin-3-y1)isoindol or $( \pm)$-phthalimidoglutarimide] (Scheme 1) was removed from the market when its teratogenic side effects, best described as heavy dysmelia (stunted limb growth), appeared in new born children shortly after its introduction. In fact, inadequate tests were performed before its release to assess the drug's safety, with catastrophic results for the children of women who had taken thalidomide during their pregnancies. In recent years, TD has regained scientific interest because of its potential for treating a number of otherwise intractable inflammatory skin diseases (erythema nodosum leprosum - ENL a complication of leprosy, graft

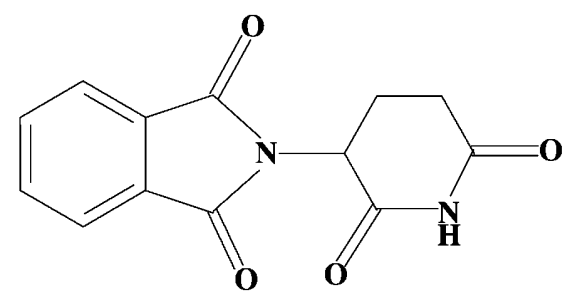

Scheme 1. Chemical structure of TD.

Electroanalysis 20, 2008, No. 22, 2429-2434 versus host disease), weight loss in tuberculosis, aphthous ulcers, wasting, human immunodeficiency virus replication in acquired immune deficiency syndrome and cancer [1-3].

TD is only sparingly soluble in aqueous solution (ca. $0.012 \mathrm{mg} \mathrm{mL}^{-1}$ ), and attempts to solubilize TD in organic solvents did not lead to therapeutic applications [4] and references therein. Biological experiments with poorly soluble drugs such as TD are seldom reproducible and have often led to misinterpretation. Precipitation leads to unreliable biological results. Consequently the in vivo mechanism of action of TD is not yet fully understood but there is some evidence suggesting that TD requires cytochrome P450 (CYP)-catalyzed biotransformation to exert its pharmacological activity. This activity includes inhibition of cellular adhesion, alternation of cell morphology and differentiation, and anti-angiogenesis. The main in vivo transformation is spontaneous nonenzymatic hydrolysis, but this pathway does not appear to be responsible for TD activity [5-7].

The oxidation of TD by CYP2C19 producing 5-hydroxythalidomide and 5'-hydroxythalidomide metabolites has been reported, and these oxidation products have also been isolated in patient's plasma and urine; 5-hydroxythalidomide $(5-\mathrm{OH})$, by hydroxylation of the phthalidomide ring possible via arene oxides, and cis- and trans-5'-hydroxythalidomide $\left(5^{\prime}-\mathrm{OH}\right)$, by hydroxylation of the glutarimide ring. 
Studies have shown that this biotransformation is stereoselective, with $(S)-(-)$-thalidomide preferentially forming $5-\mathrm{OH}$ and $(R)-(-)$-thalidomide preferentially forming trans-5'-hydroxythalidomide which epimerizes spontaneously to give the more stable cis- isomer [5-7].

On the other hand, in terms of TD teratogenicity more than 30 hypotheses have been proposed. They include hydroxyl radical mediated inhibition of angiogenesis in embryoid bodies, inhibition of growth factors, intercalation with DNA synthesis as well as oxidative damage of DNA [2, 4, 8].

Investigations of the redox behavior of biologically occurring compounds by means of electrochemical techniques have the potential for providing valuable insights into biological redox reactions of these molecules. Due to their high sensitivity voltammetric methods were used to study the redox behavior of various biological compounds [9-15]. The electrochemical reduction behavior of TD has been studied by polarography at the hanging mercury drop electrode [13-15], but its electrochemical oxidation behavior has never been investigated.

In this paper, the electrochemical oxidation and reduction mechanisms of TD hydrate, for a wide range of solution conditions, using cyclic, differential pulse and square-wave voltammetry, at a glassy carbon electrode were investigated. Information on the electrochemical behavior of TD obtained from the results at different $\mathrm{pHs}$ may play a crucial role in understanding its properties as well as its metabolism in biological system.

\section{Experimental}

\subsection{Materials and Reagents}

$( \pm)$-Thalidomide was obtained from Sigma and used without further purification. Saturated aqueous solutions of TD were prepared by shaking about $30 \mathrm{mg}$ of the compound with $5 \mathrm{~mL}$ of buffer supporting electrolyte and filtering. The filtered supernatant was used for the voltammetric experiments. All supporting electrolyte buffer solutions, Table 1, were prepared using analytical grade reagents and purified water from a Millipore Milli-Q system (conductivity $\leq 0.1 \mu \mathrm{S} \mathrm{cm}^{-1}$ ).

Table 1. Supporting electrolytes, $0.2 \mathrm{M}$ ionic strength.

\begin{tabular}{ll}
\hline $\mathrm{pH}$ & Composition \\
\hline 2.2 & $\mathrm{HCl}+\mathrm{KCl}$ \\
3.4 & $\mathrm{HAcO}+\mathrm{NaAcO}$ \\
4.5 & $\mathrm{HAcO}+\mathrm{NaAcO}$ \\
5.3 & $\mathrm{HAcO}+\mathrm{NaAcO}$ \\
6.1 & $\mathrm{NaH}_{2} \mathrm{PO}_{4}+\mathrm{Na}_{2} \mathrm{HPO}_{4}$ \\
7.0 & $\mathrm{NaH}_{2} \mathrm{PO}_{4}+\mathrm{Na}_{2} \mathrm{HPO}_{4}$ \\
8.1 & $\mathrm{NaH}_{2} \mathrm{PO}_{4}+\mathrm{Na}_{2} \mathrm{HPO}_{4}$ \\
9.3 & $\mathrm{NaOH}+\mathrm{Na}_{2} \mathrm{~B}_{2} \mathrm{O}_{7}$ \\
11.1 & $\mathrm{NaOH}+\mathrm{KCl}$ \\
12.8 & $\mathrm{NaOH}+\mathrm{KCl}$ \\
\hline
\end{tabular}

Nitrogen saturated solutions were obtained by bubbling high purity $\mathrm{N}_{2}$ for a minimum of 10 minutes in the solution and continuing with a flow of pure gas over the solution during the voltammetric experiments.

Microvolumes were measured using EP-10 and EP-100 Plus Motorized Microliter Pippettes (Rainin Instrument Co. Inc., Woburn, USA). The $\mathrm{pH}$ measurements were carried out with a Crison micropH 2001 pH-meter with an Ingold combined glass electrode. All experiments were done at room temperature $\left(25 \pm 1^{\circ} \mathrm{C}\right)$.

\subsection{Voltammetric Parameters and Electrochemical Cells}

Voltammetric experiments were carried out using a $\mu$ Autolab running with GPES 4.9 software, Eco-Chemie, Utrecht, The Netherlands. Measurements were carried out using a glassy carbon electrode (GCE) $(d=1.5 \mathrm{~mm})$ working electrode, a $\mathrm{Pt}$ wire counter electrode, and an $\mathrm{Ag} / \mathrm{AgCl}$ $(3 \mathrm{M} \mathrm{KCl})$ as reference, in a $0.5 \mathrm{~mL}$ one-compartment electrochemical cell. The experimental conditions for differential pulse voltammetry were: pulse amplitude $50 \mathrm{mV}$, pulse width $70 \mathrm{~ms}$, scan rate $5 \mathrm{mV} \mathrm{s}^{-1}$. For square-wave voltammetry the experimental conditions were frequency $25 \mathrm{~Hz}$ and potential increment $2 \mathrm{mV}$, corresponding to an effective scan rate $100 \mathrm{mV} \mathrm{s}^{-1}$.

The GCE was polished using diamond spray (particle size $1 \mu \mathrm{m})$ before every electrochemical assay. After polishing, the electrode was rinsed thoroughly with Milli-Q water. Following this mechanical treatment, the GCE was placed in buffer supporting electrolyte and various differential pulse voltammograms were recorded until a steady state baseline voltammogram was obtained. This procedure ensured very reproducible experimental results.

\subsection{Acquisition and Presentation of Voltammetric Data}

All differential pulse voltammograms presented were background-subtracted and baseline-corrected using the moving average application with a step window of $5 \mathrm{mV}$ included in GPES version 4.9 software. This mathematical treatment improves the visualization and identification of peaks over the baseline without introducing any artifact, although the peak current is in some cases reduced $(<10 \%)$ relative to that of the untreated curve. Nevertheless, this mathematical treatment of the original voltammograms was used in the presentation of all experimental voltammograms for a better and clearer identification of the peaks. The values for peak current presented in all graphs were determined from the original untreated voltammograms after subtraction of the base line.

\section{Results and Discussion}

The voltammetric behavior of TD at a GCE was investigated using cyclic voltammetry, in $\mathrm{pH} 70.1 \mathrm{M}$ phosphate 
buffer $\mathrm{N}_{2}$ saturated, supporting electrolyte (Fig. 1). TD solubility in aqueous solution (ca. $0.012 \mathrm{mg} \mathrm{mL}^{-1}$ ) is very low and the supernatant from a saturated solution prepared directly in buffer supporting electrolyte and filtrated was always used. Three peaks are observed in Figure 1, one corresponding to the reduction and two to the oxidation of TD. However, the oxidation and reduction mechanisms are independent of each other and were investigated separately.

\subsection{Oxidation}

\subsubsection{Cyclic Voltammetry}

The oxidation of TD at a GCE was studied using the supernatant from a TD saturated solution prepared directly in $\mathrm{pH} 70.1 \mathrm{M}$ phosphate buffer supporting electrolyte and filtered. The cyclic voltammogram obtained at scan rate $v=$ $100 \mathrm{mV} \mathrm{s}^{-1}$ (Fig. 2) show two well-separated consecutive

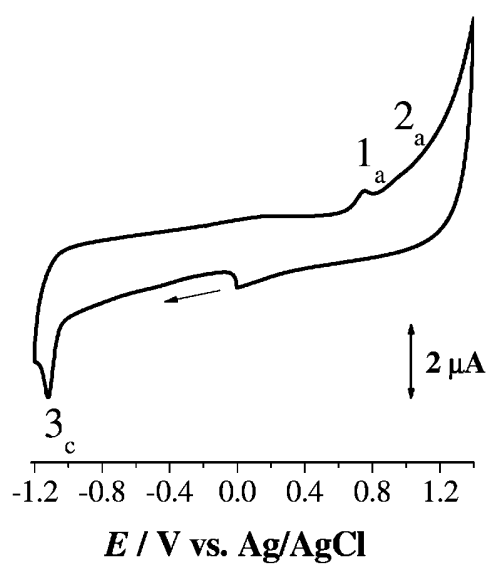

Fig. 1. Cyclic voltammogram of TD in $\mathrm{pH} 70.1 \mathrm{M}$ phosphate buffer, saturated with $\mathrm{N}_{2}, v=100 \mathrm{mV} \mathrm{s}^{-1}$.

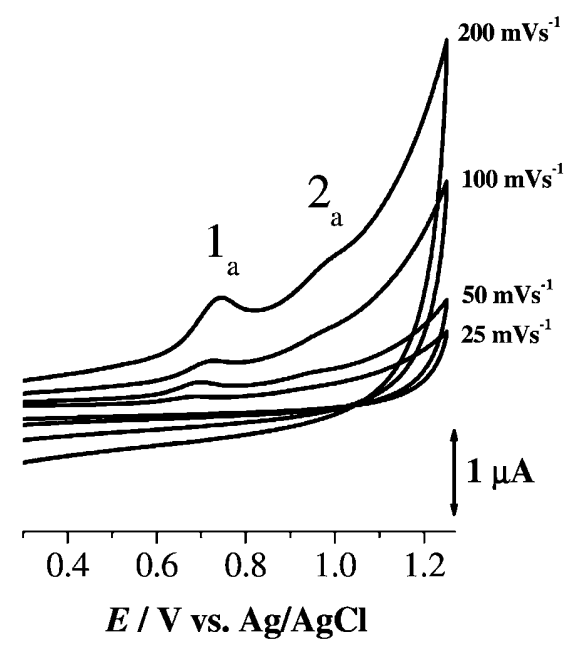

Fig. 2. Cyclic voltammograms of TD in $\mathrm{pH} 70.1 \mathrm{M}$ phosphate buffer at scan rates: $25,50,100$, and $200 \mathrm{mV} \mathrm{s}^{-1}$. oxidation peaks. Both peak $1_{\mathrm{a}}$, at $E_{\mathrm{pa}}^{1}=+0.74 \mathrm{~V}$, and peak $2_{\mathrm{a}}$, at $E_{\mathrm{pa}}^{2}=+1.10 \mathrm{~V}$, are irreversible. In the second scan a decrease of peak $1_{a}$ current and the absence of peak $2_{a}$ due to strong adsorption of TD and its oxidation products on the CGE surface was observed.

Cyclic voltammograms were also obtained for different scan rates (Fig. 2). Increasing the scan rate, the peak $1_{a}$ current also increases, but there was not a linear relationship between $I_{\mathrm{pa}}$ of peak $1_{\mathrm{a}}$ and the square root of the scan rate, as expected for an irreversible diffusion-controlled oxidation process. This is explained taking into consideration the strong adsorption of TD molecules and/or their oxidation products on the GCE surface.

\subsubsection{Differential Pulse Voltammetry}

The effect of $\mathrm{pH}$ on the electrochemical oxidation of TD was studied over a wide $\mathrm{pH}$ range between 3 and 12 using differential pulse voltammetry. The voltammograms (Fig. 3A) were all recorded in solutions of TD prepared directly in different electrolytes of $0.2 \mathrm{M}$ ionic strength and filtered.

Only one peak $1_{\mathrm{a}}$ occurs in all supporting electrolytes. For buffer solutions between $\mathrm{pH} 3$ and 9 , the potential of peak $1_{\mathrm{a}}$ is displaced to more negative values with increasing $\mathrm{pH}$ (Fig. 3A). The slope of the dotted line, $59 \mathrm{mV}$ per $\mathrm{pH}$ unit, shows that the mechanism of this oxidation process in aqueous media involves the same number of electrons and protons (Fig. 3B). The number of electrons transferred, $n$, was determined by the peak width at half height $W_{1 / 2} \approx$ $90 \mathrm{mV}$, and is close to the theoretical value of $90 \mathrm{mV}$, corresponding to an electrochemical reaction involving the transfer of one electron [16]. Consequently, it can be concluded that oxidation process occurs with the transfer of one electron and one proton.

For $\mathrm{pH}>9$, the oxidation potential of peak $1_{\mathrm{a}}$ is independent of pH (Fig. 3B), a mechanism involving only 1 electron, with the TD oxidation product possible undergoing chemical deprotonation in alkaline electrolytes [17].

However, for $\mathrm{pH}>5$ a new peak $2_{\mathrm{a}}$ appeared (Fig. 3A). The oxidation potential of the peak 2 is also $\mathrm{pH}$ dependent between 6 and 9 and its potential decreases with increasing pH (Fig. 3B). The slope of the dotted line, $59 \mathrm{mV}$ per $\mathrm{pH}$ unit, shows that the mechanism of this second oxidation process in aqueous media also involves the same number of electrons and protons. Taking into consideration that the width at half height of TD oxidation peak $2_{\mathrm{a}}$ was $W_{1 / 2} \approx$ $70 \mathrm{mV}$, the oxidation process involves the transfer of one electron and one proton.

The importance of TD ionization in the in vitro prediction of in vivo absorption has been discussed. The role of $\mathrm{pK}_{\mathrm{a}}$ on absorption is important, since this is often related to its effect on lipophilicity and solubility [18]. In order to measure $\mathrm{pK}_{\mathrm{a}}$ values, it is necessary to investigate the analyte in different $\mathrm{pH}$ environments and to monitor the variation of potential as a function of the ionization state of the molecule. The value of $\mathrm{pK}_{\mathrm{a}} \approx 9$ for $\mathrm{TD}$ was determined from data in Figure 3B. 

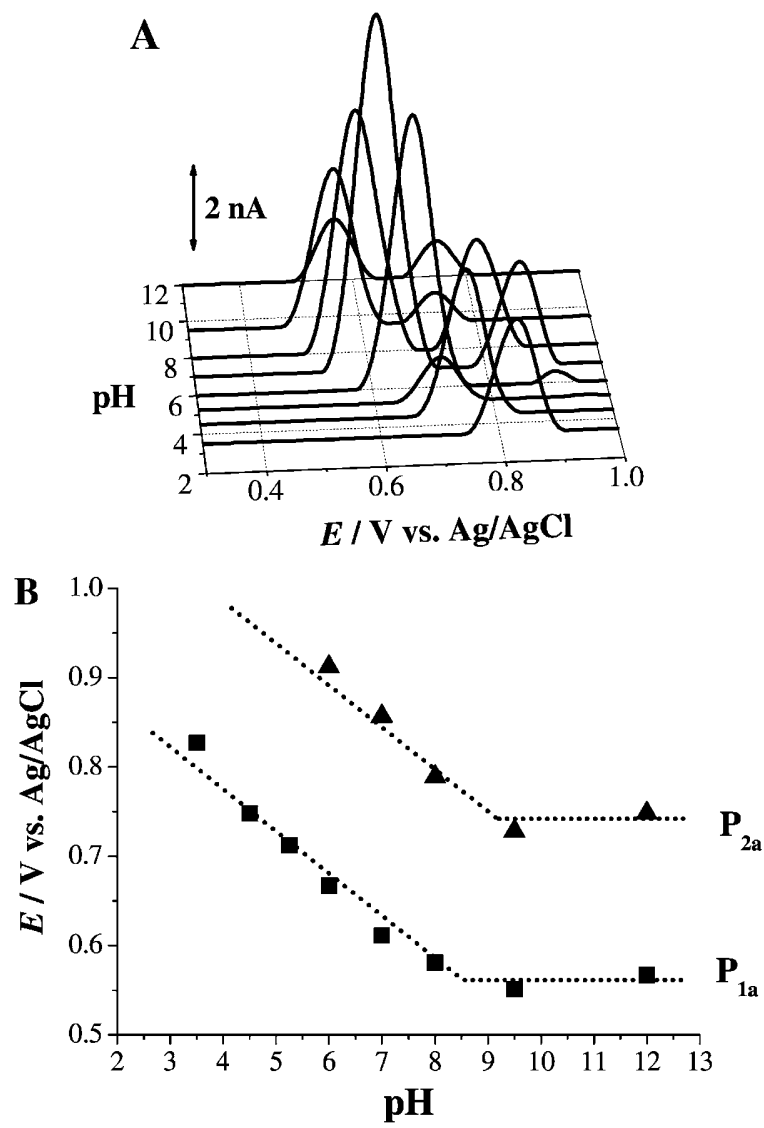

Fig. 3. A) 3D plot of oxidation background-subtracted differential pulse voltammograms obtained in TD solution as a function of pH. B) Plot of ( $\mathbf{}) E_{\mathrm{pa}}$ of peak $1_{\mathrm{a}}$ and $(\boldsymbol{\Delta}) E_{\mathrm{pa}}$ of peak $2_{\mathrm{a}}$ vs. pH. Dotted line corresponds to $59 \mathrm{mV}$ per $\mathrm{pH}$ unit.

The variation of peaks $1_{\mathrm{a}}$ and $2_{\mathrm{a}}$ current versus $\mathrm{pH}$ shows that the current increases with the $\mathrm{pH}$ (Fig. 3A), reaching a maximum in $\mathrm{pH} 70.2 \mathrm{M}$ phosphate buffer, and this electrolyte was used for further studies.

\subsubsection{Square-Wave Voltammetry}

The advantages of square-wave voltammetry are greater speed of analysis, lower consumption of the electroactive species in relation with differential pulse voltammetry, and reduced problems with the poisoning of the electrode surface [16].

The square-wave voltammograms recorded in TD solutions in different electrolytes showed similar features to the differential pulse voltammograms, i.e., the oxidation peak $1_{\mathrm{a}}$ in all buffer supporting electrolytes and the appearance of peak $2_{\mathrm{a}}$ for buffer supporting electrolytes with $\mathrm{pH}>5$, (not shown).

A greater advantage of square-wave voltammetry is the possibility to see during only one scan if the electron transfer reaction is reversible or not. Since the current is sampled in both positive and negative-going pulses, peaks corresponding to the oxidation and reduction of the electroactive species at the electrode surface can be obtained in the same
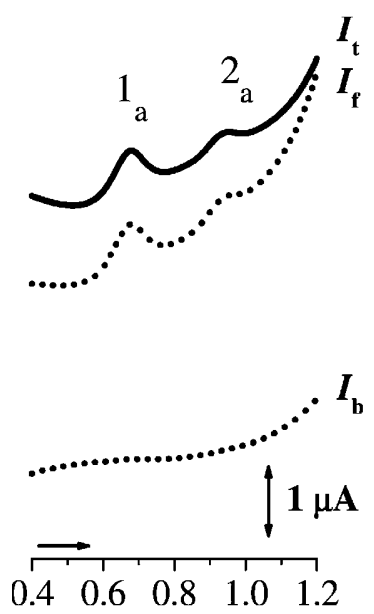

\section{E / V vs. Ag/AgCl}

Fig. 4. Square-wave voltammogram of TD in $\mathrm{pH} 70.1 \mathrm{M}$ phosphate buffer: $I_{\mathrm{t}}-$ total, $I_{\mathrm{f}}-$ forward, and $I_{\mathrm{b}}-$ backward, $v_{\text {effective }}=$ $100 \mathrm{mV} \mathrm{s}^{-1}$.

experiment. Therefore, the irreversibility of both peaks $1_{\mathrm{a}}$ and $2_{\mathrm{a}}$ was confirmed by plotting the forward and backward components of the total current obtained in a solution of TD prepared directly in pH $70.1 \mathrm{M}$ phosphate buffer (Fig. 4). Whereas the forward component showed both peaks at similar potentials as found by differential pulse voltammetry and the same total current was obtained, the backward component showed no cathodic peak.

Based on the results described a mechanism for the oxidation of TD in $\mathrm{pH} 70.2 \mathrm{M}$ phosphate buffer is proposed (Scheme 2), which in agreement with the TD data obtained using other methodologies [5, 6, 19-23]. In both oxidation steps one-electron transfer is involved, followed by deprotonation to produce a cation radical, which reacts with water and yields the final hydroxylated product.

In the first step, peak $1_{\mathrm{a}}$, one electron is removed from the phthalidomide ring, following deprotonation and the direct nucleophilic attack by water with the production of the 5-hydroxythalidomide. In the second step, peak $2_{\mathrm{a}}$, one electron is removed from the glutarimide ring, followed also by deprotonation and the direct nucleophilic attack by water with the production of 5,5'-hydroxythalidomide.

\subsection{Reduction}

\subsubsection{Cyclic Voltammetry}

The reduction of TD at a GCE was studied, due to the low solubility of TD, using the filtered supernatant from a saturated solution of a $1.1 \mathrm{mg} \mathrm{mL} \mathrm{mL}^{-1}$ prepared directly in pH 4.5 0.1 M acetate buffer supporting electrolyte. Cyclic voltammograms of TD solutions, saturated with $\mathrm{N}_{2}$, show only one reduction peak $3_{\mathrm{c}}$, at $E_{\mathrm{pc}}=-0.95 \mathrm{~V}$ (Fig. 5), in agreement with previous results obtained with the hanging mercury drop electrode [13-15]. Scanning in the positive direction, no oxidation peak was observed, showing that the 
<smiles>O=C1CCC(N2C(=O)c3ccccc3C2=O)C(=O)N1</smiles><smiles>CC(C)[AlH2]O</smiles><smiles>O=C1NC(=O)C(N2C(=O)c3ccccc3C2=O)CC1O</smiles><smiles>O=C1NC(=O)C(N2C(=O)c3ccccc3C2=O)CC1O</smiles>

Peak 2a

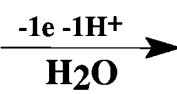<smiles>O=C1NC(=O)C(N2C(=O)c3ccc(O)cc3C2=O)CC1O</smiles>

Scheme 2. Proposed oxidation mechanism of TD in $\mathrm{pH} 7$.

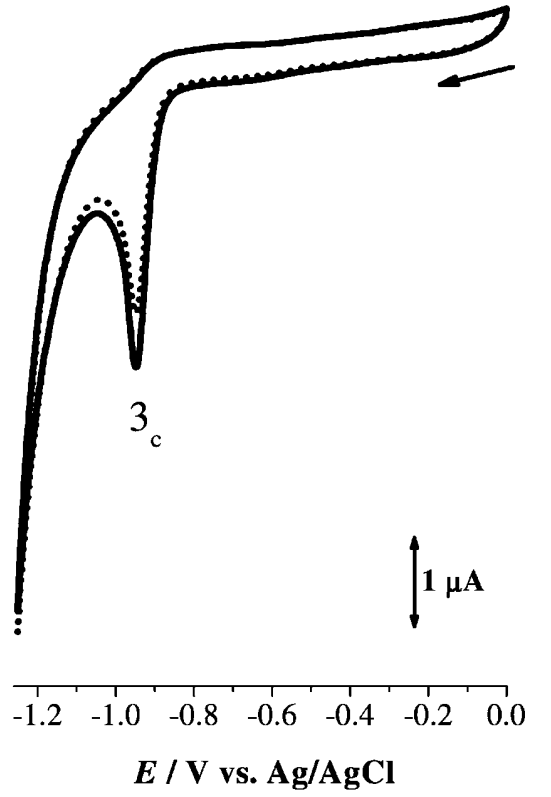

Fig. 5. Cyclic voltammograms of TD in $\mathrm{pH} 4.50 .1 \mathrm{M}$ acetate buffer, $\mathrm{N}_{2}$ saturated: (-) first and (.....) second scan, $v=$ $100 \mathrm{mV} \mathrm{s}^{-1}$.

reduction of TD in aqueous media is an irreversible process. A decrease of the reduction current occurs on successive scans due to adsorption on the GCE surface but the reduction products are not electroactive.

\subsubsection{Differential Pulse Voltammetry}

The electrochemical reduction of TD was also studied over a wide $\mathrm{pH}$ range between 2 and 12 using differential pulse voltammetry. The differential pulse voltammograms (Fig. 6A) were all recorded in solutions of TD prepared directly in different electrolytes of $0.2 \mathrm{M}$ ionic strength, filtered and saturated with $\mathrm{N}_{2}$. During the voltammetric measurements a constant flux of $\mathrm{N}_{2}$ was kept over the solution surface in order to avoid the diffusion of atmospheric oxygen into the solution of TD.

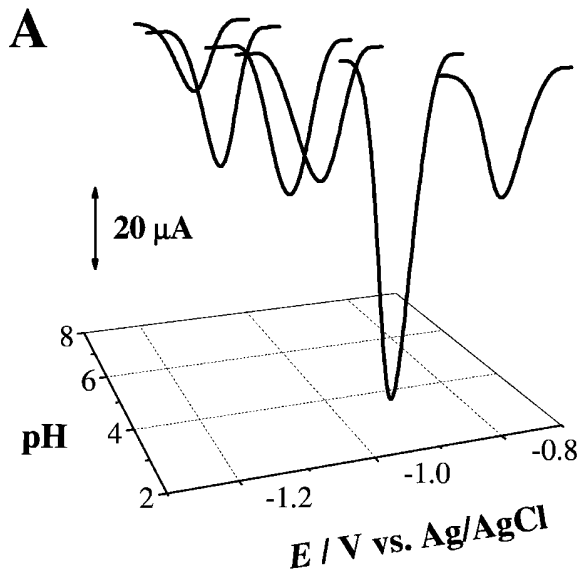

B

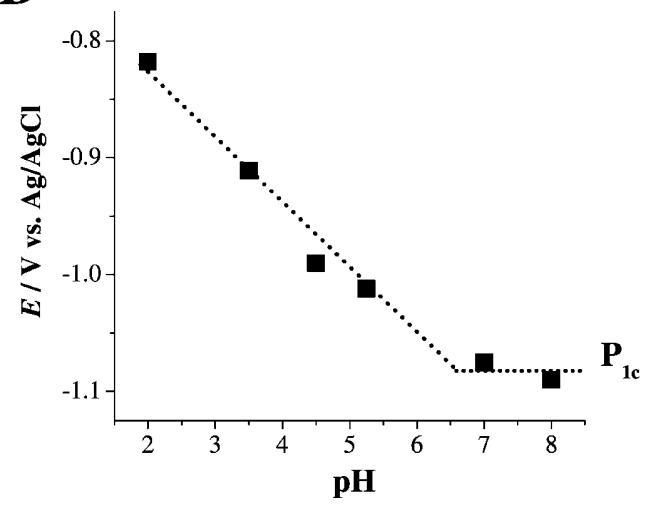

Fig. 6. A) 3D plot of reduction background-subtracted differential pulse voltammograms obtained in TD solution as a function of $\mathrm{pH}$. B) Plot of $E_{\mathrm{pc}}$ of peak $3_{\mathrm{c}}$ vs. $\mathrm{pH}$. Dotted line corresponds to $59 \mathrm{mV}$ per $\mathrm{pH}$ unit.

It was observed that peak $3_{\mathrm{c}}$ occurs only in electrolytes with $\mathrm{pH}<9$. The potential of peak $3_{\mathrm{c}}$ is displaced to more negative values with increasing $\mathrm{pH}$. The dependence is linear over the whole $\mathrm{pH}$ range between 2 and 7 (Fig. 6B). The slope of the dotted line, $59 \mathrm{mV}$ per $\mathrm{pH}$ unit, shows that the same number of electrons and protons is involved in the reduction mechanism of TD. The width at half-height of 
peak $3_{\mathrm{c}}$ was $W_{1 / 2} \approx 70 \mathrm{mV}$, so the reduction of TD occurs with one electron and one proton transfer.

The cathodic peak $3_{\mathrm{c}}, E_{\mathrm{pc}}=-0.95 \mathrm{~V}$, involves the protonation of the nitrogen that bridges the two cyclic groups, and the product of the reaction with one more proton causes the irreversible dissociation of TD.

\section{Conclusions}

The study shows that TD, a molecule with a large range of applications in biological and clinical activity, undergoes oxidation and reduction at a glassy carbon electrode.

The oxidation of TD is an irreversible adsorptioncontrolled process, $\mathrm{pH}$ dependent and occurs in two steps, leading to the formation of non electroactive oxidation products that strongly adsorb on the GCE surface. Both oxidation steps involve one electron- and one proton transfer to produce a cation radical, which reacts with water and yields the final hydroxylated product.

The reduction of TD is also an irreversible, $\mathrm{pH}$ dependent process and occurs in a single step, with the same number of electrons and protons transfer, leading to the formation of a non electroactive reduction product that strongly adsorbs on the GCE surface. The reduction involves the protonation of the nitrogen that bridges the two cyclic groups, and the product of the protonation reaction causes the irreversible dissociation of TD.

The electroanalytical determination of TD in biological fluids is foreseen and would provide very important and useful data for clinicians.

\section{Acknowledgements}

Financial support from Fundação para a Ciência e Tecnologia (FCT), Ph.D. Grant SFRH/BD/27322/2006 (S.C.B. Oliveira), projecto PTDC/QUI/65255/2006 (co-financed by the European Community Fund FEDER), and CEMUC ${ }^{\circledR}$ (Research Unit 285), is gratefully acknowledged.

\section{References}

[1] S. Tseng, G. Pak, K. Washenik, M. K. Pomeranz, J. L. Shupack, J. Am. Acad. Dermat. 1996, 35, 969.

[2] T. D. Stephens, C. J. W. Bunde, B. J. Fillmore, Biochem. Pharm. 2000, 59, 1489.

[3] S. Singhal, J. Mehta, Biomed. Pharmacother. 2002, 56, 4.

[4] S. Hess, M. A. Akermann, S. Wnendt, K. Zwingerberger, K. Eger, Bioorg. Med. Chem. 2001, 9, 1279.

[5] G. R. Macpherson, M. Franks, A. Tomoaia-Cotisel, Y. Ando, D. K. Price, W. D. Figg, Crit. Rev. Oncol. Hem. 2003, 46, 49.

[6] E. R. Leppert, N. F. Smith, M. C. Cox, C. D. Scripture, W. D. Figg, Curr. Drug Metab. 2006, 7, 677.

[7] Y. Ando, E. Fuse, W. D. Figg, Clin. Cancer Res. 2002, 8, 1964.

[8] G. E. Shull, J. Theor. Biol. 1984, 110, 461.

[9] V. C. Diculescu, T. A. Enache, A. M. Oliveira-Brett, Anal. Lett. 2007, 40, 2860.

[10] V. C. Diculescu, M. Vivan, A. M. O. Brett, Electroanalysis 2006, $18,1800$.

[11] V. C. Diculescu, M. Vivan, A. M. O. Brett, Electroanalysis 2006, 18, 1808.

[12] A. M. Oliveira-Brett, V. Diculescu, J. A. P. Piedade, Bioelectrochemistry 2002, 55, 61.

[13] J. S. Hetman, Anal. Chim. Acta 1964, 30, 313.

[14] T. Liu, M. Li, Q. Li, J. Pharm. Biomed. 2002, $29,761$.

[15] C. E. Cardoso, P. A. M. Farias, R. O. R. Martins, R. Q. Aucelio, Anal. Lett. 2005, 38, 1259.

[16] C. M. A. Brett, A. M. Oliveira Brett, Electrochemistry: Principles, Methods and Aplications, Oxford Science University Publications, Oxford 1993.

[17] S. C. B. Oliveira, V. C. Diculescu, G. Palleschi, D. Compagnone, A. M. Oliveira-Brett, Anal. Chim. Acta 2007, 588, 283.

[18] H. V. Waterbeemd, B. C. Jones, in Progress in Medicinal Chemistry, Vol. 41 (Eds: F. D. King, A. W. Oxford), Elsevier, Amsterdam 2003.

[19] F. A. Luzzio, A. V. Mayorov, W. D. Figg, Tetrahedron Lett. 2000, 41, 2275.

[20] F. A. Luzzio, E. M. Thomas, W. D. Figg, Tetrahedron Lett. $2000,41,7151$.

[21] M. Meyring, J. Muhlbacher, K. Messer, N. Kastner-Pustet, G. Bringmann, A. Mannschreck, G. Blaschke, Anal. Chem. 2002, 74, 3726.

[22] S. Erkoç, F. Erkoç, J. Mol. Struct. THEOCHEM 2005, 719, 1.

[23] P. Cipriani, C. Y. Smith, Spectrochim. Acta A. 2008, 69, 333. 